\title{
Diagnostic Accuracy
}

National Cancer Institute

\section{Source}

National Cancer Institute. Diagnostic Accuracy. NCI Thesaurus. Code C41440.

Tthe proportion of all the observations that have been classified correctly by the

diagnostic procedures in given population, or using some diagnostic test, or by some medical institution or professional. 